\title{
A ESCOLA ENQUANTO LÓCUS DE INTERAÇÃO PARA OS DESCENDENTES DE IMIGRANTES EUROPEUS DO MUNICÍPIO DE ORLEANS (SC) NO SÉCULO XIX: A LÍNGUA COMO INSTRUMENTO DESSE PROCESSO
}

\author{
Andréa Andrade Alves \\ Centro Universitário Barriga Verde - UNIBAVE. Orleans, Brasil \\ Angela Cristina Di Palma Back \\ Universidade do Extremo Sul Catarinense - UNESC. Criciúma, Brasil \\ Marcia Bianco \\ Centro Universitário Barriga Verde - UNIBAVE. Orleans, Brasil \\ Rosani Hobold Duarte \\ Centro Universitário Barriga Verde - UNIBAVE, Orleans, Brasil
}

\begin{abstract}
Resumo. O fluxo migratório europeu ao Brasil, ocorrido entre os séculos XIX e XX, contribuiu na constituição populacional do país. No estado de Santa Catarina, os imigrantes estabeleceram-se, principalmente, nas regiões Norte e Sul. Nesta última, destaca-se aqui o município de Orleans, por ser o lugar teórico de investigação, em que alemães, italianos, letos e poloneses fixaram-se, trazendo consigo toda a bagagem cultural, com ênfase nesta pesquisa, para a questão da língua materna. Portanto, o objetivo desta investigação versou em averiguar os mecanismos utilizados no ambiente escolar para promover a interação entre descendentes de imigrantes europeus do município de Orleans (Santa Catarina) no início do século XX. Com ênfase no objeto em estudo, as contribuições teóricas que permearam a presente investigação remetem-nos à concepção de língua que adotamos, i.e., do ponto de vista sociointeracionista, Nesse contexto, a investigação proposta assumiu tal concepção de língua, por entendê-la enquanto fenômeno social e cultural, que revela identidades de um povo ou nação (Bakhtin, 1981, Bortoni-Ricardo, 2004). Quanto ao percurso metodológico do que ora se socializa, fez-se uso de entrevistas, aplicadas no ano de 2014 com sujeitos da faixa etária de 68 a 91 anos, das etnias alemã, italiana, leta e polonesa, residentes no município de Orleans (SC), falantes de suas respectivas línguas maternas na infância. Os resultados obtidos apontam para a importancia da escola, por meio da aprendizagem, enquanto lócus de interação, preservação e disseminção da língua materna dos descendentes de imigrantes europeus.
\end{abstract}

Palavras-chave: Língua materna, Escola, Imigrante Europeu, Orleans, SC (Brasil).

\section{LA ESCUELA COMO LUGAR DE LA INTERACCIÓN DE LOS DESCENDIENTES DE INMIGRANTES DE LA EUROPA DE LA CIUDAD DE ORLEANS (SC) EN EL SIGLO XIX: LA LENGUA COMO INSTRUMENTO DE ESE PROCESO}

Resumen. La migración europea al Brasil, que tuvo lugar entre los siglos XIX y XX, contribuyó con la constitución de la población del país. En el estado de Santa Catarina, los inmigrantes se establecieron 
principalmente en el norte y el sur. En este último, se destaca aquí la ciudad de Orleans, siendo el lugar teórico de la investigación, donde los alemanes, italianos, letones y polacos se establecieron, trayendo con ellos todo el bagaje cultural, con énfasis en esta investigación a la cuestión de la lengua. Por lo tanto, el objetivo de esta investigación es determinar los mecanismos utilizados en el entorno escolar para promover la interacción entre los descendientes de inmigrantes europeos del municipio del Orleans (Santa Catarina) a principios del siglo XX. Con un énfasis en el objeto de estudio, las aportaciones teóricas tienen como antecedente la perspectiva sociointeracionista. En este contexto la investigación asume tal concepto de lengua por entenderla como fenómeno social y cultural que revela identidades de un pueblo o nación (Bakhtin, 1981, Bortoni-Ricardo, 2004). En cuanto al enfoque metodológico, se hizo el uso de entrevistas, implementadas en 2014 con sujetos con edades entre 68-91 años, de las etnias alemana, italiana, letona y polaca, que viven en la ciudad de Orleans (SC), que hablan sus respectivas lenguas maternas desde su infancia. Los resultados apuntan a la importancia de la escuela para el aprendizaje como lugar de interacción y la preservación y diseminación de la lengua materna de los descendientes de inmigrantes europeos.

Palabras clave: Lengua materna, Escuela, Inmigrante Europeo, Orleans, SC (Brasil).

\title{
SCHOOL AS PLACE OF INTERACTION FOR THE DESCENDANTS OF IMMIGRANTS FROM EUROPEAN ORLEANS COUNTY (SC) IN THE NINETEENTH CENTURY: LANGUAGE AS AN INSTRUMENT OF THIS PROCESS
}

\begin{abstract}
The European migration to Brazil, which took place between the nineteenth and twentieth centuries, contributed to the population constitution of the country. In the state of Santa Catarina, the immigrants settled mainly in the North and South. In the latter, stands out here city of Orleans, being the theoretical place of research, where Germans, Italians, Latvians and Polish settled, bringing with them all the cultural baggage, with emphasis on this research to the issue of language. Therefore, the aim of this research is to determine the mechanisms used in the school environment to promote interaction between descendants of European immigrants of the municipality of Orleans (Santa Catarina) in the early twentieth century. With an emphasis on the object under study, the theoretical contributions that permeated this reasearch lead us to the conception of the language from the socio-interactionism point of view. In this context, the research took that concept of language, by understanding it as social and cultural phenomenon, revealing identities of a people or nation (Bakhtin, 1981 Bortoni-Ricardo, 2004). As for the methodological approach, it was made use of interviews, implemented in 2014 with individuals from 6891 years old with German, Italian, Latvians and Polish ethnicities, living in Orleans (SC) County, speakers of their respective mother tongues in their childhood. The results point to the importance of school, through learning as the place of interaction, and the preservation and dissemination the mother tongue of the descendants of European immigrants.
\end{abstract}

Keywords: Native language, School, European immigrant, Orleans, SC (Brasil).

\section{Introdução}

O fluxo migratório europeu ao Brasil, ocorrido entre os séculos XIX e XX, contribuiu na constituição populacional do País. As etnias mais representativas desse 
contingente foram a alemã, a leta, a italiana, a polonesa, a japonesa, a suíça e a norteamericana, instalando-se em diversos estados brasileiros, entre eles São Paulo, Rio de Janeiro, Rio Grande do Sul, Paraná e Santa Catarina (Fausto, 1996).

No estado de Santa Catarina, os imigrantes estabeleceram-se, principalmente, nas regiões Norte e Sul. Nesta última, destaca-se aqui o município de Orleans, por ser o lugar teórico de investigação, em que alemães, italianos, letos e poloneses fixaram-se, trazendo consigo toda a bagagem cultural, com ênfase nesta pesquisa, para a questão da língua materna (Alves, 2015).

Nesse contexto, conforme supracitado, com foco para a questão da língua materna dos descendentes de imigrante europeu residentes no município de Orleans (SC), no início do século XX, a problemática formulada para a presente pesquisa consistiu em: qual o papel da escola na interação entre descendentes de imigrantes europeus do município de Orleans (SC) no início do século XX?

A partir do problema definido, o objetivo desta investigação versou em averiguar os mecanismos utilizados no ambiente escolar para promover a interação entre descendentes de imigrantes europeus do município de Orleans (SC) no início do século XX.

Com base nisso, a presente investigação apresenta inicialmente, a constituição identitária de Orleans (Santa Catarina), entre os séculos XVIII e XIX, com vistas a mostrar, mesmo que de modo breve, o percurso histórico acerca do fluxo migratório europeu, para compreendermos como se formou o mapa identitário do município em questão e, consequentemente, a diversidade linguística decorrente desse processo.

Com ênfase no objeto em estudo, as contribuições teóricas que permearam a presente investigação remetem-nos à concepção de língua que adotamos, i.e., do ponto de vista sociointeracionista. Nesse contexto, a investigação proposta assumiu tal concepção de língua, por entendê-la enquanto fenômeno social e cultural, que revela identidades de um povo ou nação (Bakhtin, 1981, Bagno, 2007 apud Bortoni-Ricardo, 2004).

Quanto ao percurso metodológico do que ora se socializa, fez-se uso de entrevistas, aplicadas no ano de 2014 com sujeitos da faixa etária de 68 a 91 anos, das etnias alemã, italiana, leta e polonesa, residentes no município de Orleans (SC), falantes de suas respectivas línguas maternas na infância, com cinco perguntas.

Por fim, o estudo caracteriza-se por apresentar a inserção de outras línguas em território brasileiro, especificamente no município de Orleans (SC) em decorrência do fluxo migratório europeu ocorrido entre os séculos XIX e XX, com o intuito de mostrar que a língua constitui-se em identidade cultural de determinada nação. E, ainda nesse contexto, o papel da escola enquanto lócus de interação entre os descendentes de imigrante europeu. 


\section{Orleans (SC): da colonização à diversidade linguística instalada nos séculos XIX e XX}

Para apresentar o referido município torna-se necessário retroceder no tempo. Portanto, adentramos o século XVIII no território que atualmente pertence ao município de Orleans (SC), mas que na época, estava sob o domínio do município de Tubarão (Santa Catarina). No século XVIII, os indígenas da tribo dos botocudos ${ }^{1}$ eram os únicos habitantes de uma região coberta por mata virgem e animais selvagens (Lottin, 1998).

No início do século XIX tem-se a introdução constante da passagem dos tropeiros $^{2}$ pelas terras, até então habitadas somente pelos indígenas. Eles eram responsáveis pelo transporte de gado, charque, queijos e frutas para as cidades litorâneas e retornavam à serra com sal, açúcar, aguardente e roupas (Dall’'Alba, 1996).

Devido às condições climáticas, os meios de transporte lentos, à necessidade de abertura de picadas, os tropeiros viam-se obrigados a fazer paradas regulares, construindo galpões de madeira rústicos para se abrigarem, descansarem, se alimentarem e, assim, poderem dar continuidade à viagem (Belolli, Quadros e Guidi, 2002). E foi durante uma dessas viagens que ocorreu a descoberta do carvão, conforme Lottin (1998) relata:

Por volta de 1822 uma comitiva de tropeiros, ao fazer o fogo para cozinhar, ... utilizando como de costume uma encosta de barranco e umas pedras para assentar as panelas, ficou surpresa quando observou que o fogo não apagava, além de exalar estranho cheiro de enxofre ... (Lottin, 1998, p. 54)

A notícia da possibilidade da existência de carvão na região, descoberto pelos tropeiros, foi divulgada em grande escala, alcançando a corte imperial. No ano de 1839, o governo imperial determinou a vinda do geólogo belga Dr. Jules Parigot, para averiguar a veracidade das informações. O governo apoiou financeiramente o estudo do Dr. Parigot, o qual confirmou a existência e a qualidade do carvão na região (Belolli, Quadros e Guidi, 2002).

Para Dall’Alba (1996), o interesse por parte da corte imperial nessa região acentuou-se com a descoberta do carvão e foi intensificado com o casamento entre o Conde D'Eu e a Princesa Isabel, que receberam, como presente do Imperador Dom

\footnotetext{
${ }^{1}$ Tribo indígena brasileira, do tronco macro-jê, denominada por este nome por utilizar o botoque na boca, uma espécie de ornamento feito de madeira e de forma arredondada (Almeida, 2009).

2 "O tropeiro era o responsável pelo destino da tropa e pelas relações de compra e de venda nos pontos de parada. Viajava sempre à frente ou ao fundo da tropa. Ele era a pessoa responsável pelas transações comerciais, administrava os gastos e os lucros da viagem. O tropeiro iniciava-se na profissão desde muito cedo, por volta dos 10 anos, primeiro acompanhando o pai em suas andanças quando adquiria experiência, aprendendo a negociar, a conduzir e a conviver com a lida diária da tropa. $\mathrm{O}$ tropeiro é o sucessor direto do sertanista e o precursor em muitos pontos do grande fazendeiro. O tropeiro deveria ser capaz de resolver inúmeros problemas durante a viagem. As longas jornadas exigiam que ele fosse médico, soldado, artesão, caçador, pescador, cozinheiro, veterinário, negociante, mensageiro e agricultor" (Paes, 2001, p. 76).
} 
Pedro II e da Imperatriz Teresa Cristina, um dote de terras localizado em Santa Catarina.

Deu-se início à ocupação das terras da região pelos colonos, por meio de contrato firmado entre o imperador e o Comendador Caetano Pinto Júnior, no dia 15 de novembro de 1881. O comendador foi responsável pela introdução do maior número de imigrantes na região e, no ano de 1882, Caetano Pinto Júnior decide instalar a Colônia Grão Pará, nome dado em homenagem ao primogênito do Conde D’Eu e da Princesa Isabel, D. Pedro de Alcântara Luiz Felipe Maria Gaston, Príncipe do Grão Pará ${ }^{3}$ (Dall’Alba, 1996). Sobre a colônia Grão Pará, Lottin (1998) explica:

A Colônia Grão Pará foi criada, em 1882, para promover a ocupação das terras com colonos imigrantes e nacionais. Iniciada a distribuição das terras aos imigrantes italianos, alemães, letos e poloneses desenvolveu-se paralelamente à construção da estrada de ferro para atender principalmente a região carbonífera. A escolha do local e do nome foi então por ocasião da visita de Sua Alteza o Conde d'Eu, numa viagem especial pela Estrada de Ferro, no dia 26 de dezembro 1884, que ele decidiu pela escolha dos engenheiros da empresa, apontando o local abaixo da ponte férrea sobre o Rio Tubarão (Lottin, 1998, p. 14).

Para Dall’Alba (1996), a construção da estrada de ferro Dona Thereza Cristina aconteceu, concomitantemente, à implantação da colônia Grão Pará, com o objetivo de explorar o carvão na região. Conforme dados do IBGE (Santa Catarina, 2010, p. 11) "Foi decidida a implantação de uma estrada de ferro para atender à região carbonífera e em sua construção trabalharam imigrantes de diversas procedências: italianos, alemães, letões e poloneses", sendo feita, portanto por imigrantes europeus recém-chegados na região.

No dia 2 de outubro de 1888, o município de Orleans (SC) torna-se distrito, não pertencendo mais à Colônia Grão Pará, extinguindo da empresa responsável pela Colônia os seus direitos administrativos. Com a Proclamação da República e o retorno da Família Imperial a Portugal, o patrimônio dotal pertencente aos condes é vendido, bem como a empresa Colônia Grão Pará. A referida empresa é comprada pela empresa de Terras e Colonização do Rio de Janeiro, sob a direção de Propício Barreto Pinto (Dall’Alba, 1996).

As etnias italiana, alemã, leta e polonesa foram as mais representativas no município. Os italianos vieram primeiramente da província de Trento e da região do Vêneto, no navio Scrivia.

Um dos primeiros grupos de imigrantes formados na Itália para participarem da ocupação da colônia Grão Pará foi constituído na Província de Trento, na época sob o domínio da Áustria com 137 pessoas já destinadas a ocupar lotes demarcados ao longo

\footnotetext{
${ }^{3}$ Cabe destacar que a menção à colônia Grão Pará torna-se importante para compreender o processo de constituição do município de Orleans (SC), que inicialmente pertencia a esta colônia.
} 
do vale do Rio Pinheiros. No porto de Gênova, no mês de dezembro de 1883, tomaram o navio Scrivia, um grande navio que fazia o percurso Genova - Buenos Aires com escala no Rio de Janeiro (Lottin, 2009).

Entre os anos de 1883 e 1884, eles se estabeleceram substancialmente nas comunidades rurais de Rio Pinheiros e Barracão. Na década de 1890, os alemães estabeleceram-se, inicialmente, no atual município de Braço de Norte (antes pertencente à Colônia Grão Pará). Vindos para Orleans (SC), fixaram-se na comunidade de Taipa. Os letos vieram entre os anos de 1890 e 1891. Diferentemente das demais etnias, trouxeram em sua bagagem livros e instrumentos musicais, colonizando a comunidade de Rio Novo. Os poloneses colonizaram a comunidade de Chapadão por volta de 1892 (Lottin, 1998).

O estabelecimento do imigrante europeu nas comunidades rurais do município de Orleans (SC) foi organizado pela Empresa de Terras e Colonização, instituída pelo governo brasileiro com a finalidade de subvencionar, não só a vinda, mas, sobretudo, as necessidades básicas para que o imigrante, denominado colono, pudesse viver em um país diferente de sua nação. Para isso, de acordo com Dall'Alba (2003), a Empresa estabeleceu políticas próprias de auxílio ao colono, desde subsídios para a exploração de terras, como sementes e ferramentas, até a permissão para implantar igrejas e escolas nas comunidades, a fim de criar uma esfera de respeito às nacionalidades.

Nas escolas instituídas em comunidades rurais do município de Orleans (SC), a partir do século XX, especialmente nas comunidades de colonização europeia, o ensino acontecia na língua materna do imigrante, o que se constituía, conforme Santos (2009), como forma de preservar a identidade do imigrante europeu estabelecido em terras brasileiras.

A esse respeito, Seyferth $(2000$, p, 148) observa que: “... a localização de imigrantes de uma mesma origem nacional em áreas circunscritas facilitou uma organização comunitária étnica e a manutenção do uso cotidiano da língua materna." A posição de Seyferth (2000) é reforçada pela fala de Carvalho (2008), ao considerar que a construção da identidade de determinada nação está estritamente vinculada à língua materna desse povo.

E é a partir dessa perspectiva que, na próxima seção, discutiremos conforme mencionado anteriormente, acerca de língua na concepção sociointeracionista.

\section{Concepção de língua}

Nesta seção, apresentaremos conceitos de língua, associando, na medida do possível, aos pressupostos da Sociolinguística Educacional, conciliando permanentemente à visão interacionista de linguagem, esboçada nas seções precedentes deste referencial, enfatizando que a linguagem é sociológica, constrói o próprio sujeito. 
Como até aqui apresentado, a concepção de língua defendida, entendendo-a como elemento fundante da identidade cultural, bem como de sua dinâmica que envolve a alteridade entre sujeitos para significar os discursos socialmente colocados, daí a visão sociointeracionista.

Os conceitos de linguagem, língua e signo linguístico foram organizados primeiramente por Saussure, em 1916, na França, tido como o pai da Linguística. Seus estudos foram sistematizados e reconhecidos como ciência na obra Curso de Linguística Geral, organizada pelos discípulos do professor (Goldfeld, 1997). Sobre isso, de acordo com Costa (2008):

Para Saussure a linguagem é social e individual; psíquica; psico-fisiológica e física...., a Língua é definida como a parte social da linguagem e que só um indivíduo não é capaz de mudá-la. “..., a língua é um sistema supra-individual utilizado como meio de comunicação entre os membros de uma comunidade", portanto "a língua corresponde à parte essencial da linguagem e o indivíduo, sozinho, não pode criar nem modificar a língua.” (Costa, 2008, p. 116).

Na concepção saussuriana discutida por Costa (2008), a língua é um sistema que não pode ser manipulado ou submetido ao indivíduo. Para Barreto (2009), a língua não é materializada, é uma abstração da realidade que só se concretiza por meio da fala. É um sistema de signos cuja essência é a união do sentido e da imagem acústica. É importante inserir aqui a discussão de Souza (1994):

Ao separar a língua (social) da fala (individual), Saussure irá priorizar e estudar apenas os elementos constituídos pelas formas normativas da língua, supondo ser esta um produto que o sujeito registra passivamente. Para o objetivismo abstrato, o fator normativo e estável prevalece sobre o caráter mutável da língua e, portanto, esta é vista como um produto acabado, transmitido através das gerações. Dessa forma, o que interessa não é a relação do signo com a realidade por ele refletida ou com o indivíduo que o engendra, mas a relação do signo para o signo no interior de um sistema de signos. Portanto o signo é considerado independentemente das significações ideológicas que a ele se ligam. (Souza, 1994, p. 97-98)

Bakhtin (1981) formula uma crítica à epistemologia de Saussure, demonstrando que reduzir a linguagem a um sistema abstrato de formas constitui-se obstáculo à apreensão da natureza real da linguagem como código ideológico e fenômeno histórico e social. Souza (1994) enfatiza a concepção de Bakhtin ao dizer que:

Bakhtin irá mostrar que a linguagem só pode ser analisada, na sua devida complexidade, quando considerada como fenômeno sócio ideológico e apreendida dialogicamente no fluxo da história. Sua concepção de linguagem vai ser construída a partir de uma crítica radical às grandes correntes [à época] da lingüística contemporânea, por considerar que essas teorias não trabalham a língua como fenômeno social. (Souza, 1994, p. 93, grifo nosso) 
Saussure e Bakhtin parecem comungar do conceito de língua enquanto fato social, cuja existência se funda na necessidade da comunicação. Entretanto, Bakhtin contrapõe-se à linguística de Saussure, a qual faz da língua um objeto abstrato e refuta suas manifestações individuais como a fala. Bakhtin valoriza a fala e a compreende como constitutiva da língua, afirmando sua natureza social.

A fala está indissoluvelmente relacionada à comunicação e, consequentemente, permanentemente associada às estruturas sociais (Bakhtin, 1981). O referido autor acrescenta:

Os indivíduos não recebem a língua pronta para ser usada; eles penetram na corrente da comunicação verbal; ou melhor, somente quando mergulham nessa corrente é que sua consciência desperta e começa a operar .... Os sujeitos não "adquirem a língua materna; é nela e por meio dela que ocorre o primeiro despertar da consciência." A verdadeira substância da língua ... é constituída ..., pelo fenômeno social da interação verbal, realizada através da enunciação ou das enunciações. A interação verbal constitui assim a realidade fundamental da língua. (Bakhtin, 1981, p. 108-123)

A teoria de Bakhtin define que o centro organizador de toda expressão é o exterior do indivíduo, i.e., o meio social. Todos os diversos campos da atividade humana estão conectados ao uso da linguagem. Nesse sentido, tratar de língua e, consequentemente, de ensino de língua na escola, é necessariamente entender a escola como um micro aspecto da sociedade (Valadares e Bragança, 2012).

Cabe aqui enfatizar que a escola, enquanto parte integrante do meio social, constitui-se, também lócus cultural da sociedade, na qual a língua se manifesta, constrói relações e identidades. Portanto, torna-se importante seguir esse raciocínio pelo fato de nossa pesquisa centrar-se no ensino de língua em um ambiente escolar. Nessa linha de pensamento, encontra-se também o entendimento de Bagno, Stubbs e Gagné (2002, p. 32), que definem a língua como: “... uma atividade social, cujas normas evoluem segundo os mecanismos de auto-regulação dos indivíduos e dos grupos em sua dinâmica histórica de interação entre si e com a realidade ..."

Bakhtin (1981, p. 113) defende a ideia de língua em uma perspectiva interacionista ao afirmar que: "... a palavra constitui justamente o produto da interação do locutor e do ouvinte. Toda palavra serve de expressão a um em relação ao outro". Nessa concepção, o indivíduo usa a língua em seu contexto social como forma de interação nas relações existentes no grupo social em que está envolvido, ponto que nos permite a conciliação com os teóricos anteriormente mobilizados neste referencial.

Conceber a língua, segundo Labov ([1972] 2008, p. 220), como “... um instrumento de comunicação usado pela comunidade de fala ...” e, portanto, como convenção social pelas suas peculiaridades, permite-nos, nas próximas seções, abordar a sociolinguística, em um primeiro momento, como uma teoria que assegurou ampla 
descrição da variação e mudança do sistema linguístico e, em um segundo, como contribuição a uma teoria ainda emergindo: a Sociolinguística Educacional.

... parece muito mais interessante (por ser mais democrático), estimular, nas aulas de língua, um conhecimento cada vez maior e melhor de todas as variedades sociolinguísticas, para que o espaço de sala de aula deixe de ser o local para o estudo exclusivo das variedades de maior prestígio social e se transforme num laboratório vivo de pesquisa do idioma em sua multiplicidade de formas e uso. (Bagno, Stubbs e Gagné, 2002, p. 32)

O exposto por Bagno, Stubbs e Gagné (2002) traz à baila a importância de conceber o ensino de língua no ambiente escolar pelo entendimento do uso dela em sua variedade percebida no contexto social. Em face disso, iniciaremos nosso diálogo com o que nos interessa enfatizar, tomando a Sociolinguística Educacional como fundamentação, buscando entendimento necessário do ensino de língua heterogênea, sobretudo em contextos bilíngues e/ou multilíngues, como parece ser o caso do contexto no qual a pesquisa se desenvolve, de modo a descrever e analisar junto ao capítulo seis, de análise dos dados.

Os primeiros estudos sobre sociolinguística datam da década de 60 do século XX pelo linguista norte-americano William Labov (1968). Labov descreve a língua a partir de seu uso variável. Contrapondo-se aos conceitos até então predominantes de língua, enquanto sistema homogêneo, estático e independente da presença de uma comunidade de fala, o linguista apresenta, com a sociolinguística, o conceito de língua com base em suas variantes sistemáticas, motivadas pelas ações sociais, devendo, portanto, ser estudada, imbricada ao contexto social em que ela se faz presente (Weinreich, Labov, Herzog, [1968] 2006). Eis a teoria da Variação e Mudança, cujo recorte sintético pode ser visto por meio da fala que segue:

A Teoria da Variação ... situa-se em relação ao conjunto língua e sociedade, considerando a variedade das formas em uso como objeto complexo, decorrente dos fatores internos, próprios do sistema linguístico, e dos fatores sociais que interagem no ato da comunicação. Uma teoria da mudança deve, pois, conceber a língua - de um ponto de vista diacrônico e/ou sincrônico - como um objeto possuidor de heterogeneidade sistemática. (Hora, [20--], p. 99)

Antes de apresentarmos as contribuições de anos de pesquisa dos sociolinguistas, a partir da descrição linguística, aos estudos da Sociolinguística Educacional, cabe destacar uma diferença da concepção de língua que trouxemos anteriormente, filiada às ideias de Bakhtin (1981) e da concepção de Labov (1966; 1968; 1972), no quesito língua enquanto sistema individual e social, ambos imbricados e passíveis de transformações pela condição de uso.

$\mathrm{Na}$ concepção laboviana, a língua é o objeto-alvo nos estudos da sociolinguística, por ser o instrumento utilizado pelas e entre as pessoas para se comunicar no cotidiano. Para Labov (1966), não há discussões explícitas acerca dos 
jogos ideológicos que se encerram junto aos signos linguísticos, muito embora o linguista lide com variáveis sociais que podem, sim, remeter a um conjunto interpretativo do ponto de vista ideológico, a exemplo dos estudos clássicos de Labov (1966) sobre as manifestações do [r] de trabalhadores das lojas de departamento de Nova York (Sacks e Macy’s), junto às quais se podiam observar estratificação social por meio dos usos da língua. Enfim, o uso é elemento central nos discursos (Labov, 1966 apud Back, 2008).

Com o foco direcionado para a língua em uso no contexto social da comunidade de fala, encontramos fundamento naquilo que Figueroa (1994, p. 76 apud Severo, 2009, p. 270) define como filiação teórica à Durkheim; citando-a: "Sabe-se que Labov é familiarizado com Durkheim, que ele utiliza o termo fato social, que ele aceita a língua como fato social". Os fatos sociais referem-se a “... maneiras de agir, de pensar e de sentir, que apresentam a propriedade marcante de existir fora das consciências individuais" (Durkheim, 1973, p. 2 apud Severo, 2009, p. 270). A propriedade, que podemos depreender da existência do sujeito no coletivo, permite-nos um ponto de conexão com as ideias de Bakhtin, por considerar a língua inserida em um contexto social, na perspectiva de interação com o outro, o que se constrói significativamente no coletivo.

Para Gobber e Morani (2010), a sociolinguística estuda as diversas possibilidades de realização de uma língua determinadas pelas diferenças sociais e ambientais dos falantes. A identificação de uma variedade, em que uma comunidade linguística é reconhecida, em oposição a outras variedades contíguas. Assim, a língua também surge como fonte de identidade de um grupo ou uma comunidade.

De acordo com Coan e Freitag (2010, p. 192), a sociolinguística tem por finalidade “... o estudo da heterogeneidade sistemática da língua”, pois “... possibilita o entendimento das diferenças linguísticas condicionadas por diferentes espaços geográficos, comunidades, classes sociais, faixas etárias, níveis de formalidade, entre outros". As contribuições de Back (2000) sobre sociolinguística são importantes no que tange à sociolinguística variacionista, ao defini-la como:

... uma das sub-áreas da Sociolingüística e tem como objeto de estudo a variação lingüística, propriedade que se apresenta como inerente a todas as línguas. Sua proposta teórica constrói o objeto (a variação lingüística) como um todo heterogêneo, entendendo ser esse todo heterogêneo passível de descrição e análise. $\mathrm{O}$ fenômeno da variação parece ser contínuo, ... aponta para tendências de formas que são condicionadas por fatores diversos. ... de natureza interna (lingüísticas) e de natureza externa (social). (Back, 2000, p. 30)

Cabe destacar, conforme exposto por Back (2000), que a variação linguística tem por fatores condicionantes de estudo os de natureza interna e externa, isto é, linguística e social respectivamente. E, nessa perspectiva, está o foco desta pesquisa, 
considerando a escola enquanto espaço social, responsável pela disseminação e preservação da língua do imigrante europeu, população-alvo desta investigação.

\section{Método}

O método de pesquisa selecionado para a investigação é história oral, utilizando como técnica a entrevista, por permitir o registro dos fatos históricos segundo a impressão dos próprios protagonistas, ampliando o universo dos dados obtidos, necessários para determinada investigação (Freitas, 1998).

Portanto, selecionamos dez pessoas, na faixa etária dos 68 a 91 anos, residentes no município de Orleans (SC) e descendentes das etnias alemã, italiana, leta e polonesa. No primeiro contato, para cada sujeito, foi apresentado o propósito da pesquisa. Ressaltamos que tivemos o cuidado de obter o Termo de Compromisso Livre e Esclarecido (TCLE) definido por Freitas (1998), como importante para firmar o vínculo entre a pesquisadora e o(s) entrevistado(s) participante(s).

A técnica utilizada foi a entrevista, tendo-se o cuidado de que o entrevistado se sentisse à vontade e, para isso, escolhesse o local que transmitisse e permitisse o acesso a objetos pessoais, como documentos, fotografias, acessórios, dentre outros, propiciando um ambiente de naturalidade, familiaridade, acolhimento e principalmente estímulo à rememoração das lembranças necessárias à pesquisa que se pretendia desenvolver. A esse respeito, Thompson (1998, p. 107) destaca que "O importante é que o local de realização da entrevista contribua para se atingir os objetivos que a geraram e não prejudique a realização estabelecida, nem a gravação do depoimento". Acrescido a isso, reportamo-nos a Back (2000), sob a perspectiva laboviana do 'paradoxo do observador', i.e., a importância de o pesquisador criar a atmosfera acolhedora e estruturada de tal forma que o entrevistado se sinta seguro e tranquilo para discorrer sobre o assunto tratado. A coleta de dados se deu no período de maio a setembro do ano de 2014.

Ao iniciarmos a transcrição das entrevistas, observamos algumas situações ocorridas, que nos fizeram tomar decisões sobre a melhor maneira para transcrevê-las, a fim de torná-las legíveis. Alguns exemplos dessas situações são: a incompreensão do dito; a continuidade de determinado assunto, sem fazer referência à resposta a ele; a inserção de falas de outras pessoas que estavam presentes no momento da entrevista, dentre outras.

Portanto, optamos por seguir somente as necessárias normas de transcrição do Projeto de Estudo da Norma Linguística Urbana Culta no Brasil (Projeto NURC) ${ }^{4}$ e do

\footnotetext{
${ }^{4}$ O Projeto de Estudo da Norma Linguística Urbana Culta no Brasil (Projeto NURC) teve início em 1969 e vem se desenvolvendo em cinco cidades brasileiras - Recife, Salvador, Rio de Janeiro, São Paulo e Porto Alegre. Objetiva descrever os padrões reais de uso na comunicação oral adotados pelo estrato social constituído de falantes com escolaridade de nível superior." (PRETI e URBANO, 1990).
} 
Laboratório de Pesquisas de Letras (LAPEL) ${ }^{5}$, da Universidade do Extremo Sul Catarinense - UNESC, Criciúma (Santa Catarina).

Para a delimitação da amostra de nossa pesquisa, tomamos inicialmente as orientações de Meihy (2002), ao explanar sobre a necessidade de haver "a comunidade de destino, colônia e as redes de pessoas a serem entrevistadas" (Meihy, 2002, p. 64).

A comunidade de destino, de acordo com Meihy (2002), refere-se ao grande grupo que a pesquisa pretende abranger. Neste caso, a nossa investigação adotou como critérios: pessoas de ambos os gêneros, residentes no município de Orleans (SC), inseridas na faixa etária de 68 aos 91 anos. Portanto, para fazermos a seleção da amostra com base nos critérios supracitados, averiguamos inicialmente o contingente populacional por gênero e faixa etária do município de Orleans (SC), pelos dados estatísticos do IBGE (Santa Catarina, 2010), os quais identificam um total de 1219 pessoas (homens e mulheres) na faixa etária de 68 a 91 anos, o que em nossa pesquisa torna-se importante destacar, por considerar que esse grupo etário nasceu entre as décadas de 1920 e 1940 e isso vem ao encontro de um dos critérios que estabelecemos para selecionar a população-alvo pertencente à investigação, i.e., pessoas que falavam a língua materna (estrangeira) na infância.

Sobre as colônias, Meihy (2002, p. 165) destaca que elas são qualificadas “.... pelos padrões gerais de sua comunidade de destino, isto é, pelos traços preponderantes que ligam a trajetória de pessoas a grupos amplos." Nessa perspectiva, nossa pesquisa voltou-se para os seguintes critérios: descendentes das etnias alemã, italiana, leta e polonesa, falantes na infância de sua língua materna.

No entanto, cabe-nos aqui fazer algumas considerações. $\mathrm{O}$ resultado obtido com os dados do IBGE (sobre a população) refere-se ao ano de 2010, portanto são os dados mais atuais que temos. Contudo, há a possibilidade de inserção de mais pessoas nesse grupo etário, assim como considerar o fator de mortalidade, que pode ter ocorrido no grupo etário apresentado na Tabela 1, entre os anos de 2010 e 2014, informação que o instituto não oferece.

Outra variável que o IBGE (Santa Catarina, 2010) não agrega à pesquisa referese à etnia e, por isso, não houve possibilidade de identificar a quantidade de pessoas pelas etnias que compõem nossa pesquisa: alemã, italiana, leta e polonesa.

Por último, não são fornecidos pelo Instituto dados referentes ao nome e local de residência, por serem confidenciais e, portanto, não permissíveis de divulgação pública.

Assim, partindo dessa realidade e com base na última etapa da seleção - as redes de pessoas a serem entrevistadas - proposta por Meihy (2002) e entendida como os grupos de pessoas que efetivamente fariam parte da pesquisa -, adotamos algumas estratégias para localizar os possíveis sujeitos participantes.

\footnotetext{
${ }^{5}$ Para mais informações, averiguar em: <http://www.unesc.net/portal/capa/index/220>.
} 
Por conta das constatações supracitadas, entre os meses de agosto e setembro do ano de 2014, fizemos uso de duas estratégias, na tentativa de localizar nossa populaçãoalvo: fomos às unidades de saúde do município, pelo fato de essas instituições terem o cadastro dos pacientes e, portanto, terem duas informações importantes: idade e local de residência. Outra estratégia que adotamos foi o contato com populares, pelas amizades constituídas e, com isso, a facilidade de conseguir nomes e endereços de prováveis pessoas que poderiam compor nossa amostra.

Com base nisso, o nosso roteiro de busca da população-alvo percorreu geograficamente as comunidades rurais de Barracão, Taipa, Invernada e Chapadão, além dos bairros Barro Vermelho e Centro, pois parte delas foi colonizada pelos imigrantes europeus.

Como resultado dessa etapa da pesquisa, conseguimos obter a amostra da população de nossa investigação, conforme Tabela 1 .

Tabela 1. População-alvo selecionada para a pesquisa por faixa etnia, gênero e grau de escolaridade.

\begin{tabular}{|c|c|c|c|c|c|c|c|c|c|c|}
\hline \multirow{4}{*}{ Etnia } & \multirow{4}{*}{ Idade } & \multirow{2}{*}{\multicolumn{8}{|c|}{$\begin{array}{c}\text { Grau de escolaridade }^{6} \\
\begin{array}{c}\text { Ensino Fundamental } \\
\text { (em anos) }\end{array}\end{array}$}} & \multirow{4}{*}{ } \\
\hline & & & & & & & & & & \\
\hline & & \multicolumn{2}{|c|}{$1^{\circ}$} & \multicolumn{2}{|c|}{$2^{\mathbf{o}}$} & \multicolumn{2}{|c|}{$3^{\circ}$} & \multicolumn{2}{|c|}{$4^{\circ}$} & \\
\hline & & $\mathbf{M}$ & $\mathbf{F}$ & $\mathbf{M}$ & $\mathbf{F}$ & M & $\mathbf{F}$ & $\mathbf{M}$ & $\mathbf{F}$ & \\
\hline \multirow{4}{*}{ Alemã } & 80 & 1 & - & - & - & - & - & - & - & \multirow{4}{*}{4} \\
\hline & 80 & - & - & - & - & - & - & 1 & - & \\
\hline & 74 & - & - & - & - & - & - & 1 & - & \\
\hline & 88 & - & - & - & - & - & 1 & - & - & \\
\hline \multirow{3}{*}{ Italiana } & 86 & - & - & - & - & - & 1 & - & - & \multirow{3}{*}{3} \\
\hline & 80 & - & - & - & - & - & 1 & - & - & \\
\hline & 91 & - & - & - & 1 & - & - & - & - & \\
\hline \multirow{2}{*}{ Leta } & - & - & - & - & - & - & - & - & - & \multirow{2}{*}{1} \\
\hline & 68 & - & - & - & - & - & - & - & 1 & \\
\hline \multirow{2}{*}{ Polonesa } & 80 & - & - & - & - & - & 1 & - & - & \multirow{2}{*}{2} \\
\hline & 81 & - & - & - & 1 & - & - & - & - & \\
\hline
\end{tabular}

Fonte: Dados da pesquisa (2014)

Há que se fazer uma observação pertinente na Tabela 1, no que diz respeito à quantidade de pessoas selecionadas, remetendo-nos às orientações de Freitas (1998) e Meihy (1998), que destacam a importância da qualidade das entrevistas e não da quantidade de pessoas entrevistadas, sinalizando que a primeira está vinculada à consubstancialidade dos dados obtidos, com a devida propriedade das pessoas que

${ }^{6} \mathrm{O}$ grau de escolaridade refere-se ao prescrito na Lei de Diretrizes e Bases da Educação - LDB n. ${ }^{\circ}$ 9496/96 (Brasil, 1996). No momento histórico que contextualiza esta pesquisa, conforme o Regulamento Geral da Instrucção Pública de 1913 (Santa Catharina, 1913), o ensino era estruturado em: primário, ginasial, secundário e superior. 
vivenciaram o momento histórico que se discute na pesquisa. Os entrevistados têm idade média de 68 a 91 anos.

Como não podemos citar nomes de pessoas, conforme o Termo de Compromisso Livre e Esclarecido (TCLE), a identificação dos sujeitos participantes desta pesquisa, verificada na próxima seção, dar-se-á de maneira geral pelas nomenclaturas 'entrevistado (a)' ou 'sujeito'. Individualmente adotamos códigos com três dígitos, sendo duas letras e um número. A primeira refere-se à etnia, por exemplo: A = alemã; a segunda retrata o gênero: $\mathrm{M}=$ masculino e $\mathrm{F}=$ feminino. $\mathrm{O}$ número foi colocado aleatoriamente e mantido para cada entrevistado, do início ao fim.

\section{Resultados}

- Pistas de um (ou alguns) vernáculo (s) construído (s), constituído (s), identitário (s)

Com o propósito de averiguar os mecanismos utilizados no ambiente escolar para promover a interação entre descendentes de imigrantes europeus do município de Orleans (SC), no início do século XX, uma das hipóteses que guiou a entrevista foi a de que o processo de ensino-aprendizagem ocorria na língua do imigrante de igual origem étnica, o que favoreceria, por um lado, a disseminação e a preservação da língua na comunidade onde determinada etnia se fixava. Consequentemente, a interação na família e na comunidade também ocorreria na língua do imigrante. Com essa perspectiva em mente, salienta-se que a discussão agrega ao debate as perspectivas da sociolinguística educacional, compreendendo a língua enquanto fator de identidade cultural.

Em face disso, 5 (cinco) foram as questões que visavam a verificar em que medida a hipótese era atestada. A primeira foi: Você poderia nos dizer como era sua infância, a sua vida na comunidade, brincadeiras, enfim o convívio com outras pessoas e cotidiano?

A pergunta teve por propósito favorecer a proximidade necessária entre a pesquisadora e o sujeito, lembrando aqui as discussões labovianas acerca do paradoxo do observador ${ }^{7}$, de modo a trazer à memória dos entrevistados as lembranças da infância, o que, por um lado, faria com que ele retornasse ao passado de modo a imergir intensamente nele, fazendo com que o entrevistado não monitorasse a forma em que se manifesta a língua, pois poderia aí se revelar o vernáculo em cuja realização estariam formas ligadas à língua de cultura.

As ocorrências a seguir, de (1) a (12), ilustram vários elementos que poderiam contribuir para que se materializasse o vernáculo, para a análise de características de identidade cultural por meio do uso da língua. Vejamos:

\footnotetext{
${ }^{7}$ Para mais informações, ver Back (2008).
} 
1) AF2 - "É..., fui desde a idadi de seis anos que eu me lembro. Carpiná, isso eu inda não fazia, né! Porque era mui fraquinha pra isso, né! Pegá inxada. Mas nóis, eu gostava de ajudá, ajuntá raiz de mandioca, batata, essas coisa né, milho, enchia os balaio. Aí eu disse e o pai é... [falou em alemão]. (risadas) ${ }^{8}$. [negrito nosso]

O dado (1), da entrevistada AF2 ilustra casos considerados importantes para trazer à discussão, tendo em vista o uso do português não padrão (variação linguística) ${ }^{9}$ em vários segmentos da entrevista, como, por exemplo, nos substantivos: 'idadi' e 'inxada', em que ocorre a substituição das vogais /e/ por /i/, muito comum no português não padrão, inclusive em função de um ritmo que aí se estabelece. Pode-se, ainda, visualizar no excerto a supressão do segmento /r/ no final dos verbos: 'carpiná' e 'ajuntá', os quais também destaca o uso de um subsistema linguístico em contraposição à norma culta, que se confere ter sido ensinada a esta entrevistada no ambiente escolar quando criança.

Entre os fatores que estão associados à constituição dos falares, Bortoni-Ricardo (2004) destaca possíveis causas dessas variações, como a divisão em falares rurais e urbanos, os estágios de desenvolvimento social e os fluxos migratórios ocorridos no Brasil nos séculos XIX e XX. Variações essas presentes no dado (1), em que se percebe, pelo destaque de falas em língua alemã, ser evidenciada entre falantes que vivem em comunidades bilíngues. Esse fenômeno, de acordo Von Borstel (2001), consiste no uso/alternância de dois sistemas ou subsistemas gramaticais paralelamente a um mesmo ato comunicativo de falantes bilíngues; esse fenômeno não pode ser visto como um processo aleatório, ou seja, somente a troca de meros vocábulos na superfície (significantes) ou estruturas sintáticas causais, mas sim:

... a existência de elementos motivacionais discursivos e/ou de natureza sóciopragmática na realização dos enunciados híbridos. ... pode ser utilizado em contextos sociais para a transmissão de significados sutis - como identificação étnica e cultural, papéis/hierarquia dos participantes da interação, valores sociais e situacionais, etc. (Soares e outros, 2012, p. 7)

É a partir do horizonte posto em Soares (op. cit), que acreditamos, ajudar-nos a interpretar ocorrências como $(1)^{10}$, pois o uso de dois sistemas linguísticos no decorrer da fala está impregnado de valores étnicos e culturais que perpassaram o espaço de

${ }^{8} \mathrm{O}$ modo como está transcrita a materialidade discursiva (a fala) tenta explicar as regularidades da variação linguística manifesta sem exprimir juízos. As outras ocorrências apresentam, via de regra, grande parte das regularidades aqui observadas, mas procuraremos transcrevê-las o mais próximo possível do padrão de escrita.

${ }^{9}$ Podemos listar alguns elementos de análise linguística detectados no dado (1), como por exemplo, a supressão de segmentos iniciais, mediais e finais nas palavras 'inda' e 'inxada', 'otro' e 'pegá' respectivamente; a inserção de segmentos (ditongação) em 'nóis' e 'os balaio'. Porém, o nosso propósito não está em fazer uma análise criteriosa do ponto de vista da forma. Esses dados serviram apenas para ilustrar as possibilidades, lembrando que essa perspectiva não está inserida nos objetivos da pesquisa, no entanto pode abrir expectativas para investigações futuras.

${ }^{10}$ Aqui foi um exemplo trazido de várias ocorrências de igual teor identificadas nos dados coletados. 
tempo entre a ocorrência do fenômeno que estamos discutindo e que constitui o vernáculo que se manifesta no momento de interação entre os sujeitos.

Entretanto, a constituição do vernáculo, em uma comunidade, dá-se com o uso das línguas materna e estrangeira em situação cotidiana de intensa interação, em que os sistemas coabitam, remetendo às discussões de Bakhtin (1981), em que o sujeito apreende a língua por meio da interação verbal, ele a internaliza, influencia e é influenciado por ela, em um processo de reciprocidade contínuo.

Outra questão posta para dar início ao tema foi: Havia associações ou clubes na comunidade em que vivia? O que proporcionavam aos imigrantes? (educação, trabalho, lazer, política, cultura, entre outros)?. Seu propósito foi o de adentrar à temática da educação, mais especificamente quanto ao uso da língua, por meio de elementos sociais que permitissem a interação entre os membros de igual origem étnica e, consequentemente, o fortalecimento de suas características étnicas e culturais. Nessa perspectiva, a seguir têm-se as ocorrências (2) e (3) para ilustrar esse propósito:

(2) IM5 - "Tinha um clube ali no Barracão. Quando era pequeno, depois passou no Rio Carlota, do lado do Cape. Acabei a aula do lado do Cape porque ali no Barracão tinha um professor. ... depois passei aqui no Rio Carlota. Era perto, era ali na capela”.

(3) PM9 - "É lá é uma escola ... eu não me recordo. Até eu sei que a igreja velha, depois fizeram a igreja nova. A igreja velha serviu de sala de aula também. Depois fizeram outra maiorzinha e ...".

Os dados (2) e (3) representam a maioria das respostas dos entrevistados, por constatar a existência de escola e igreja nas localidades ou proximidades onde habitavam e, muitas vezes, a estrutura física da igreja servindo como escola. A esse respeito, temos as considerações de Dall’Alba (2003), ao referir-se ao momento da vinda dos imigrantes para Orleans (SC), no final do século XIX, subvencionados pela Empresa de Terras e Colonização, responsável pelo transporte, hospedagem e auxílio aos imigrantes recém-chegados, a qual permitia aos colonos a implantação de igrejas e escolas nas comunidades, com o propósito de possibilitar um ambiente acolhedor e de respeito às nacionalidades e horizontes culturais.

O compromisso que parece estar assegurado nas ações da empresa exibe respeito a essas culturas, por conceber, conforme Kreutz (1999), a identidade do ser humano representada no caráter étnico, e que este "... é elemento de diferenciação social, influi na percepção e na organização da vida social. Ele não se dá no abstrato. Manifesta-se nos símbolos, nas representações e na valorização de grupos." (Kreutz, 1999, p. 79-96). Portanto, a escola e a igreja tendem a representar os elementos étnicos da cultura do imigrante, para que ele pudesse sentir-se em uma esfera próxima àquela em que vivia em sua terra natal. 
Seguindo essa linha de raciocínio, temos a língua como constituinte essencial nesse processo de fortalecimento das características de nacionalidade de um determinado grupo social, no caso em específico que estamos analisando, do imigrante europeu e seu descendente, convergindo com as ideias de Bakhtin (1981), ao asseverar que "não existe absolutamente nada na cultura além da palavra, que toda a cultura não é nada mais que um fenômeno da língua" (Bakhtin 1981, p. 45). Ou seja, língua e cultura estão imbricadas.

A hipótese aqui é a de que a 'língua em uso' considerada como manifestação de uma cultura, passa a ser central quando consideramos a pergunta mais direta: A família se comunicava em que língua? E com os amigos, como era a comunicação (língua)?, buscando mapear em que medida ocorria a comunicação na língua do imigrante e seus descendentes, cuja hipótese é confirmada a partir dos dados (4), (5), (6) e (7) a seguir:

(4) AM1 - "Primeiramente falavam em... em língua, é, é em alemão? É, eu tinha doze anos por ali mais ou menos. Em alemão também tem mais, mais diálogo, assim, mais idiomas assim em alemão, não é uma só né. Por exemplo tem, tem [falou palavras e dialetos em alemão] 'Folen',', 'Westphalen',12, 'Plat ${ }^{\prime 13}$... É ... eu ... também tinha 'Postruiten'14 ... mas é assim, a linguagem da minha mãe era ali 'Huonriten' 15 e o meu pai era mais 'Wetsphalen'. [explicação em alemão]. E assim... em casa nós falava mais assim... puxava mais pela mãe né, aquilo que ela falava mais é... era...”.

Aqui queremos fazer um parêntese sobre outro aspecto importante no dado (4) da resposta do entrevistado AM1, segundo o qual havia a existência de vários dialetos alemães na própria comunidade em que vivia (aqui), conforme atestam Rosa, Damke e Von Borstel (2008, p. 3):

A língua falada pela maioria dos imigrantes era o alemão em sua variedade dialetal, trazida da Alemanha, chamada Hunsrückisch, uma vez que os primeiros imigrantes vieram, em grande maioria, da região do Hunsrück. Vale destacar que não era somente desta região que vieram os primeiros imigrantes, mas também ... das mais variadas regiões da Alemanha e de outros países onde se falava o alemão...

Justifica-se, dessa forma, a variedade dialetal informada pelo entrevistado AM1, assim como o entrevistado AM3, o qual informou a existência de duas línguas (dialetos alemães) entre os membros de sua família.

O que se verifica com a ocorrência (4) da etnia alemã, também se constata junto aos dados (5), (6) e (7) sobre a comunicação nas outras comunidades étnicas:

\footnotetext{
${ }^{11}$ Kölsch

${ }^{12}$ Vestphalenisch

${ }^{13}$ Plattdüütsch

${ }^{14}$ Não conseguimos identificar

${ }^{15}$ Hunsrück
} 
(5) IF7 - "Tudo italiano, tutto! Tutto italiano!"

(6) LF8 - "Tudo em leto. Sim, muito leto... É, não, aí com os amiguinhos, quem era leto a gente falava em leto..."

(7) PM9 - "Tudo, tudo, era tudo. [em polonês] ... o falecido pai tinha pra me ensinar. Mas, é... uma cartilha polonesa era fácil pra ler... e eu tinha facilidade pra ler... é, mas criança também, sempre tem facilidade pra ... aprender as coisas..."

Constatamos, nos dados (4), (5), (6) e (7), que todos se comunicavam em suas línguas maternas (alemã, italiana, letã e polonesa), tanto em casa quanto no convívio com os parentes e amigos de igual origem.

A esse respeito, as respostas dos entrevistados comungam com Carvalho (2008, p. 83) ao dizer que “... a construção da identidade de uma nação está vinculada à língua falada por este povo". Por isso, as comunidades de imigrantes europeus e seus descendentes, ao se instalarem no município de Orleans (SC), no final do século XIX e início do século $\mathrm{XX}$, estabeleceram comunicação entre seus pares com suas línguas maternas, muito embora, diante da obrigatoriedade do uso do português via ensino sistematizado, ainda conseguissem assegurá-las de certo modo, permanecendo, dessa maneira, sua identidade cultural por meio dessas línguas em uso, no ambiente socialmente constituído por eles, conforme podemos perceber nas considerações de Rosa, Damke e Von Borstel (2008):

Os imigrantes, ao chegarem às terras brasileiras, tiveram que se adaptar ao clima, às condições de vida rudimentares e ao idioma. Assim que chegaram foram alocados em regiões distantes de outras colônias ou aglomerações urbanas, ou seja, ficaram isolados geograficamente o que foi um dos motivos que, de maneira bastante expressiva, a língua de seu país de origem se conservasse. (Rosa, Damke e Von Borstel, 2008, p. 3)

E é nesse ambiente, no meio social em que o sujeito vive, que Bakhtin (1981) acentua que o indivíduo constrói e é constituído socialmente na aquisição da língua.

Dando sequência à análise, a pergunta que se colocou foi: Havia escola para os imigrantes? Era mantida por quem? Essa questão teve o propósito de confirmar a existência de escolas subvencionadas pelos governos das etnias representativas no município de Orleans (SC), pois acreditamos que a ação conjunta, entre os governos dos países de origem dos imigrantes e seus descendentes e estes, favorecia o processo de fortalecimento da identidade cultural, já que o ensino nessas escolas, hipotetizamos, ocorria na língua do imigrante e seus pares. No entanto, a resposta da maioria dos entrevistados não nos trouxe informações suficientes para responder à questão posta, falando da escola em si, seu funcionamento, localização, entre outras apreciações. 
Contudo, nessa situação, buscamos entender o funcionamento do ensino em Santa Catarina entre as décadas de 1920 e 1940, no Regulamento Geral de Instrucção Pública - RGIPSC (Santa Catharina, 1913, p. 19), o qual dispunha no Título II, do Ensino em Geral, Capítulo Único - do Ensino Público - Art. 39, dispõe que "o ensino público será dado: a) na Escola Normal; b) nas Escolas Complementares; c) nos Grupos Escolares; d) nas escolas preliminares, intermediárias, provisórias e ambulantes; e) nas escolas municipais, ...", sendo os dois primeiros de responsabilidade do Governo Federal e os três últimos de responsabilidade dos Governos Estadual e Municipal. Os três últimos tipos supracitados são denominações atribuídas às escolas primárias do Estado (Santa Catharina, 1913).

Além desses tipos, o Regulamento fazia referência ao Ensino Privado, que poderia “... ser exercido livremente, salvo quando for subsidiado pelos cofres públicos, quer estadual quer municipaes" (Santa Catharina, 1913, p. 19).

No município de Orleans (SC), Lottin (1998) registra que, entre o final do século XIX e início do século XX, as escolas existentes eram particulares. No caso das escolas criadas pelos colonos, a maioria era subvencionada pelos governos dos países de origem. Somente a partir do ano de 1913, com a emancipação do município, o governo municipal cria novas escolas e subvenciona parte daquelas (particulares) já existentes. Assim, podemos crer, com base nas fontes pesquisadas, que parte das escolas, em que os descendentes europeus estudavam, era particular e outra parte era pública.

Por fim, a questão: Em que língua ocorria o ensino na escola? visou a confirmar a hipótese de que o ensino no ambiente escolar ocorria na língua do imigrante. Vejamos os dados (8), (9) e (10) na sequência:

(8) AM3 - “... só, falava só em alemão ... É ... Em alemão. É ... em alemão, conversava em alemão. Então passava, as tabuada, as coisa, tudo em alemão."

(9) AF4 - "Nós tivemos em alemão um ano .... Era, no primeiro ano foi. ... ali era $p$... (dialeto). $O$ ' $m$ ' é só assim [gesticulou a letra], o ' $m$ 'é só assim ... alguma coisa da letra, o 'd'é assim que nós fizemos e o dele é assim (gesticulou novamente).". 16

(10) IM5 - "O tempo do professor H. nós falava em italiano e ele falava em italiano. Primeiro sim." [No início da década de 1930]

Os dados (8) e (9) dos entrevistados AM3 e AF4 confirmaram que, na escola, o ensino era feito em língua alemã, assim como o dado (12) do entrevistado IM5, em língua italiana, permitindo-nos analisar as informações obtidas sob dois aspectos. $\mathrm{O}$ primeiro aspecto, com base em Dall'Alba (1996), confirma a existência de escolas particulares subvencionadas pelos colonos e o governo de sua terra natal. Nessas

${ }^{16}$ A entrevistada comenta que a língua que a professora ensinava era diferente da língua que ela sabia, que havia aprendido em casa. Ela descreve como dois dialetos alemães (Dados da pesquisa, 2014). 
escolas, o ensino era feito na língua materna do imigrante, afirmando por um lado o dado (10).

Os desdobramentos dessa situação colocam em evidência o caráter de ensino de língua associada às questões socioculturais das comunidades. Sobre isso, BortoniRicardo (2004, p. 45) observa que: "A tarefa educativa da escola, em relação à língua materna, é justamente a de criar condições para que o educando desenvolva sua competência comunicativa e possa usar, ... para desempenhar-se bem nos contextos sociais em que interage." Assim, podemos crer, conforme os dados (8), (9) e (10), que o ensino era feito na língua materna do imigrante com o objetivo de criar um ambiente de favorecimento, para além da escola, no âmbito social, de fortalecimento dos seus valores culturais por meio da língua.

\section{Considerações finais}

Este trabalho explicitou o modo como esteve colocada a presença das línguas maternas dos imigrantes europeus e seus descendentes no município de Orleans (SC), devido à colonização destes a partir do século XIX, sobretudo na escola, no processo de ensino-aprendizagem.

Por meio desta pesquisa, identificamos, nas respostas dos sujeitos, que todos falavam as suas respectivas línguas maternas na infância, nas variadas esferas sociais (casa, igreja, por exemplo), assim como no ambiente escolar, formatando um vernáculo, respeitando a característica cultural da língua de origem.

Vale destacar, por meio da análise dos dados obtidos com as entrevistas aplicadas, a constituição da multiplicidade linguística no município de Orleans (SC), por conta da presença de imigrantes europeus e seus descendentes na região; de modo que com isso, trouxeram toda a bagagem cultural de seus países de origem, manifestada, sobretudo na e pela língua, difundindo-a e preservando-a (inclusive e, sobretudo, a língua), tanto no âmbito escolar quanto nos diversos segmentos sociais, como constructo de suas identidades culturais.

Por fim, enfatiza-se aqui, a importância da escola nesse contexto, por constituirse enquanto lócus de interação dos imigrantes e seus descendentes, por meio da aprendizagem e preservação de suas respectivas línguas maternas. Pois, conforme constatado nas entrevistas, a comunicação em outras esferas sociais acontecia na língua materna do imigrante (e seus descendentes). Sendo a escola, o espaço formal de aprendizagem, e, além disso, de disseminação de um elemento importante que caracteriza a identidade cultural de determinado povo ou nação, que é a língua. 


\section{Referências}

Almeida, M. R. C. de. (2009). Índios, mestiços e civilizados de Debret: reflexões sobre relações interétnicas e mestiçagens. Varia História. 25(41), 85-106. Recuperado em 20 de março de 2014, de http://www.scielo.br/pdf/vh/v25n41/v25n41a05.pdf.

Alves, A. A. (2015). Educação em língua materna de quem? O descendente europeu em Orleans (SC) no contexto da política nacionalista de Vargas (1930). Dissertação Mestrado em Educação. Universidade do Extremo Sul Catarinense - UNESC. Criciúma (SC).

Back, A. C. Di P. (2000). O uso variável do quantificador universal no sintagma nominal na língua falada de Florianópolis. Dissertação de Mestrado em Linguística. Universidade Federal de Santa Catarina, Florianópolis. Recuperado em 20 de março de 2014, de http://repositorio.ufsc.br/xmlui/handle/123456789/79301.

Back, A. C. Di P. (2008). A multifuncionalidade da forma verbal-sse no domínio do tempo - aspecto - modalidade: uma abordagem sincrônica. Tese de Doutorado em Lingüística. Universidade Federal de Santa Catarina, Florianópolis. Recuperado em 20 de janeiro de 2014, de https://repositorio.ufsc.br/bitstream/handle/123456789/90868/262662.pdf?seque nce $=1 \&$ is Allowed $=\mathrm{y}$.

Bakhtin, M.M. (1981) Marxismo e filosofia da linguagem. São Paulo: Hucitec.

Belolli, M., Quadros, J. e Guidi, A. (2002). História do Carvão de Santa Catarina. Florianópolis: Imprensa Oficial do Estado de Santa Catarina. Recuperado em 27 de janeiro de 2013, de http://www.satc.edu.br/siecesc/pdf/livro_carvao/a_historia_do_carvao_de_santa _catarina.pdf.

Bortoni-Ricardo, S. M. (2004). Educação em língua materna: a sociolinguística na sala de aula. 6. ed. São Paulo: Parábola Editorial.

Bortoni-Ricardo, S. M. e Freitas, V. A. de L. (2009). Sociolinguística Educacional. In Hora, Dermeval e outros (orgs). Abralin - 40 anos em cena. João Pessoa: Editora UFPB. Recuperado em 27 de janeiro de 2014, de http:www.stellabortoni.com.br/index.php/projetos/../30-banco-de-dados?.

Carvalho, J. R. (2008). A Construção da Identidade de uma Nação por meio da Língua Escrita e Falada. Revista Fórum Identidades. Sergipe, Ano 2, v. 4, p. 83-90, jul./dez. Recuperado em 14 de março de 2015, de http://200.17.141.110/periodicos/revista_forum_identidades/revistas/ARQ_FOR UM_IND_4/SESSAO_L_FORUM_Pg_83_90.pdf. 
Coan, M. e Freitag, R. M. K. (2010). Sociolinguística variacionista: pressupostos teórico-metodológicos e propostas de ensino. Domínios de Linguagem - Revista Eletrônica de Linguística, 4(2), 173-194. Recuperado em 17 de janeiro de 2014, de

http://www.seer.ufu.br/index.php/dominiosdelinguagem/article/viewFile/11618/ 6863.

Costa, M. (2008). Estruturalismo. In M. E. Martelotta e outros (Org.). Manual de Lingüística. São Paulo: Contexto.

Dall’Alba. J. L. (1996). Colonos e mineiros no Grande Orleans. Florianópolis: Edição do Autor.

Dall’Alba. J. L. (2003). Colonos e mineiros no Grande Orleans. Reimp. Florianópolis: Edição do Autor.

Fausto, B. (1996). História do Brasil. 2a . ed. São Paulo: EDUSP. Recuperado em 14 de maio de 2015, de http://www.usp.br/cje/anexos/pierre/FAUSTOBorisHistoriadobrasil.pdf.

Freitas, S. M. de.(1998). História Oral: procedimentos e possibilidades. São Paulo: Associação Editorial Humanitas. Recuperado em 21 de agosto de 2014, de file:///C:/Users/Andrea/Downloads/6936360-Historia-Oral-Procedimentos-ePossibilidades-Sonia-Maria-de-Freitas.pdf.

Gobber, G. e Morani, M. (2010). Linguistica Generale. New York: The McGraw-Hill Companies. Recuperado em 21 de março de 2015, de http://www.ateneonline.it/gobber/studenti/risposte/isbn6493-9_risposte_01.pdf.

Goldfeld, M. (1997). A criança surda. São Paulo: Plexus Editora.

Hora, D. [(20--)]. Sociolinguística. Paraíba: Universidade Federal da Paraíba. Recuperado em 21 de março de 2015, de http://portal.virtual.ufpb.br/bibliotecavirtual/files/sociolinguastica_1360184257.pdf.

Kreutz, L. (1999). Identidade étnica e processo escolar. Caderno de Pesquisa. n. 107 (p. 9-96). Recuperado em 16 de março de 2015, de http://www.scielo.br/pdf/cp/n107/n107a03.pdf.

Labov, W. (1966). Language in the inner city: studies in the black english vernacular. Philadelphia: University of Pennsylvania,

Labov, W. (1968). Modelos sociolingüísticos. Trad. José Miguel Marinas Herreras. Madrid: Cátedra.

Labov, W. (1972). Padrões Sociolinguísticos. Trad. Marcos Bagno, Maria Marta Pereira Scherre, Caroline Rodrigues Cardoso. São Paulo: Parábola.

Lottin, J. Orleans 2000: história e desenvolvimento. (1998). Florianópolis: Elbert.

Lottin, J. Retratos de Orleans. (2009). Orleans: Copiart. Recuperado em 14 de março de 2015, de 
http://www.jucelylottin.net.br/Livro\%20Retratos\%20de\%20Orleans.pdf.

Meihy, J. C. S. B. (1998). Manual de História Oral. 2. ed. São Paulo: Loyola.

Meihy, J. C. S. B. (2002). Manual de história Oral. 4. ed. São Paulo: Loyola.

Paes, J. M. (2001). Tropas e Tropeiros na primeira metade do século XIX no alto sertão baiano. 164 f. (Dissertação). Mestrado em História - Universidade Federal da Bahia. Salvador, 2001. Recuperado em 10 de fevereiro de 2014, de http://www.ppgh.ufba.br/wp-content/uploads/2013/12/Tropas-e-tropeiros-naprimeira-metade-do-seculo-XIX.pdf.

Preti, D. e Urbano, H. (Org.) (1990). A linguagem falada culta na cidade de São Paulo. v. 4. São Paulo: T. A. Queiro, Fapesp.

Rosa, E. K., Damke, C. e Von Borstel, C. N. (2008). Língua/Cultura como fator de pertencimento identitário. In $14^{a}$ Jornada Regional e $4^{o}$ Nacional de Estudos Linguísticos e Literários - Campus da UNIOESTE. Marechal Cândido Rondon. Paraná. Recuperado em 6 de março de 2014, de http://www.letras.ufscar.br/linguasagem/edicao19/artigos/artigo_013.pdf.

Santa Catarina. (2010). Instituto Brasileiro de Geografia e Estatística - IBGE. Dados do município de Orleans (SC). Recuperado em 16 de abril de 2014, de http://www.sidra.ibge.gov.br.

Santa Catharina. (1913). Regulamento Geral da Instrucção Pública em execução da Lei $n^{o} 967$ de 22 de agosto de 1913. Recuperado em 16 de abril de 2014, de file:///C:/Users/Andrea/Downloads/Regulamento_Geral_Instruc\%C3\%A7ao_Pu blica_02_maio_1914\%20-\%20(1).pdf.

Santos, A. V. dos. (2009). A política educacional nacionalista e o aspecto linguístico: vestígios na escola primária. Estudos RBEP. Brasília, 90(225), 511-527, maio/ago. Recuperado em 16 de maio de 2014, de http://rbep.inep.gov.br/index.php/RBEP/article/viewFile/1270/1237.

Severo, C. G. (2009). O estudo da linguagem em seu contexto social: um diálogo entre Bakhtin e Labov. DELTA. 25(2), 267-283. Recuperado em 16 de junho de 2014, de http://www.scielo.br/scielo.php?script=sci_arttext\&pid=S010244502009000200003.

Seyferth, G. (2000). A identidade dos imigrantes e o melting pot nacional. Horizontes Antropológicos, (6)14, 143-176. Recuperado em 15 de fevereiro de 2015, de http://www.scielo.br/pdf/ha/v6n14/v6n14a07.

Soares, M. S. e outros (2012). A alternância de códigos no contexto da educação bilíngue: code-switching, code-mixing e as transferências lingüísticas. Revista Gatilho, 8(15). Recuperado em 16 de junho de 2014, de http://www.ufjf.br/revistagatilho/files/2012/11/15-soares.pdf.

Souza, S. J. e. (1994). Infância e linguagem: Bakhtin, Vygotsky e Benjamin. Campinas (SP): Papirus. 
Thompson, P. (1998). A voz do passado: história oral. 2. ed. Rio de Janeiro: Paz e Terra.

Valadares, F. B. e Bragança, M. L. L. (2012). Bakhtin e Linguística Aplicada: Ações Metodológicas na Construção do Ensino de Língua Portuguesa. Revista PerCursos Linguísticos, 2(6), 29-45.

Von Borstel, C. N. (2001). O code switching sobre a visão do modelo variacionista. UniLetras, 23(1). Recuperado em 13 de setembro de 2015, de http://eventos.uepg.br/ojs 2/index.php/uniletras/article/viewFile/220/218.

Weinreich, W., Labov, W. e Herzog, M. (1968). Empirical Foundations for Theory of Language Change. In P. Lehmann e Y. Malkiel. Directions for Historical Linguistics. Austin: University of Texas Press. Fundamentos empíricos para uma teoria da mudança linguística. Pp. 27-56. Trad. Marcos Bagno. São Paulo: Parábola Editorial.

Data de recebimento: $21 / 04 / 2016$

Data da revisão: 22/05/2016

Data do aceite: 20/07/2016 